638 Hermann Aubert: Die Genanigkeit der Ophthalmometer-Messungen.

für den horizontalen Meridian) a $\mathrm{n}$ s c h m i e g t, wïrde nach Feststellung des $<\alpha$ in der Weise zu berechnen sein, wie man aus den Gradmessungen der Erdmeridiane die elliptische Gestalt derselben bestimmt hat, indem man aus den Combinationen der einzelnen gemessenen, näher oder weiter von einander entfernten Punkten die wabrscheinlichen Curven bestimmt und aus denselhen das Mittel nimmt. Dabei wird sich dann ergeben, ob diese Curve eine geschlossene ist, ob sie ein Kreis, eine Ellipse, eine Parabel oder Hyperbel ist, und welcher dieser Curven die gemessene Krümmung der Hornhaut am nächsten kommt.

Mit Hülfe meines verehrten Collegen, Herrn Professor Mat thiessen, welchem ich viele Belehrungen anch für die bisherigen Beobachtungen verdanke, hoffe ich weitere Untersuchungen der menschlichen Hornhaut, welche auch für die vergleichend-anatomischen Untersuchungen über die Hornhautkriummung von grossem Interesse sein dürften, in der nächsten Zeit durchzuführen.

\title{
Bemerkungen über die Physiologie der, Verdauung bei den Batrachiern.
}

Von

Dr. P. Grützmer (Tübingen) und Dr. H. v. Swiecieki (Posen).

Im 48. Bande dieses Archivs S. 63 hat Sigmund Fränkel eine Arbeit, betitelt: „Beiträge zur Physiologie der Magendrüsen“ veröffentlicht, in welcher er gegen eine Untersuchung ${ }^{1}$ ), die der eine von uns (S.) als Student unter Anleitung des Anderen (G.) angestellt hat, mehrfache Einwendungen macht. Zweck dieser Zeilen ist es, diese Einwendungen zurückzuweisen.

Zunächst wenden wir uns gegen folgenden gleich im Anfang der Arbeit Fränkel's stehenden Satz: „Als im Jahre $1876 \mathrm{Sw}$ ięcicki nachgewiesen haben wollte, dass beim Frosche im Oesophagus Pepsin, im Magen nur Salzsäure gebildet wird, während in

1) Dieses Archiv Bd. 13, S. 444. 
dem letzteren bloss delomorphe Zellen vorkommen, schien der Gedanke von diesen verschiedenen Functionen der beiden Zellarten so sehr gefestigt, dass Heidenhain ihn in Hermann's Handbuch der Physiologie (S. 135) als eine durch gewichtige Thatsachen gerechtfertigte Theorie lehren konnte."

Der bei weitem wichtigste und von Keinem bestrittene Punkt, nämlich die Pepsinbereitung in den Oesophagusdruisen, die ein alkalisches fermentreiches Secret liefern, während die Magenschleimhaut unzweifelhaft die Säure bildet, wird auch von Fränkel anerkannt. Wobl aber wendet er sich gegen die angebliche Behauptung von Swiẹcicki, dass, wie es auch Heidenhain (S. 137 u. 149) darstellt, in dem Magen des Frosches, der nur Belegzellen oder denen ähnliche Gebilde führt, n u r Säure und gar kein Pepsin gebildet wird. Indessen bestreiten wir, dass Fränkel zu dieser Behauptung berechtigt ist; denn in der genannten Arbeit von Swięcicki findet sich als das Ergebniss der verschiedenen nach dieser Richtung hin angestellten Versuche der Satz: „Alle diese Thatsachen sprechen hiernach dafür,

dass bei den Fröschen die Pepsinbildung vorzugsweise, ja vielleicht nur allein in dem Oesophagus von Stattè geht, während der die Belegzellen führende Magen die Sä ure bildet."

Dieser in genannter Arbeit (so wie hier) gesperrt gedruckte Passus giebt unsere damalige, dem Leserkreise dargebotene Anschauung über die betreffende Frage wieder, gegen welche allein irgend ein Angriff zu richten gewesen wäre. Es ist aber in ihr durchaus nicht die Behauptung ausgesprochen, dass im Magen n u r die Sänre and $\mathrm{nur}$ im Oesophagus das Pepsin gebildet werde, sondern jene Frage betreffend die Pepsinbildung ist vorsichtiger Weise offen gelassen, da úns alle Versuche ergaben, dass auch aus der Magenschleimhaut, wenn auch bedeutend viel weniger Pepsin, als ans der Oesophagussehleimhaut durch die bekannten Mittel extrahirt werden konnte. Daher unsere Behauptung, dass der Magen für sich kein verdauungsfähiges Secret zu bilden im Stande ist; denn selbst angenommen, dass er Pepsin bildet, ist diese Pepsinmenge eben so gering, dass sie auch im Verein mit einer passenden Säure als ein verdauungsfähiges und verdaungskräftiges Secret, welches eben in einer bestimmten, nicht allza langen Zeit 
seine Arbeit verrichten muss, nicht angesèhen werden kann. Soviel über die formale Seite dieser Frage.

Was nun das S a chliche derselben anlangt, so behaupten wir, dass Fränkel nicht mehr, sondern sogar weniger positives thatsächliches Material zur Lösung derselben beigebracht hat, als wir. Seine ersten Versuche zeigen, dass man aus der Oesophagusund Magenschleimhaut Pepsin extrahiren kann. Sie enthalten aber nicht die geringste Angabe darüber, wie viel etwa Pepsin aus der einen oder anderen Schleimhaut extrahirt wurde, sondern besagen weiter nichts, als dass beide Auszuige "Fibrin sebr rasch verdauten". Unsere Versuche zeigen sehr genau, wie rasch beide Auszïge verdauten, nämlich der des Magens ausserordentlich viel langsamer als der des Oesophagus.

Die zweite Versuchsreihe Fränkel's ergab, dass wenn man den Oesophagus von dem Magen durch Einführung eines festen Stopfens abtrennt, dann die Magensehleimhaut noch ein saures, pepsinhaltiges Secret lieferte. Sieht man sich aber den Versuch genauer an, so ist gesagt, dass die in Tüllsäckchen eingefithrten Fibrinflocken, die ja nur sehr klein gewesen sein konnten, in 24 Stunden verdaut waren. Nun, wenn Fränkel mit dieser Leistung des Magens zufrieden ist, dann ist er unerlaubt bescheiden. Fast jedes thierische Gewebe und jede Flüssigkeit (Muskel, Darm, Speichel, Harn) verdauen, in passender Weise mit Säuren behandelt, viel energischer oder wenigstens nicht langsamer als dieser Froschmagen. Die Abschnürungsversuche Frànkel's beweisen also auch nicht einen Deut mehr als diejenigen von Swięcicki, betreffend die peptische Kraft der lebenden Magenschleimhaut, über welche sich dieser folgendermaassen ausspricht: „In den durch eine Ligatur vom Oesophagus abgeschniirten Magen wurden dureh eine Oeffnung im Duodenum Fleischstückchen eingefuhrt, der Magen selbst dann in der Nähe des Duodenum unterbunden und sein Inhalt nach 24 'Stunden untersucht. Das Fleisch war nicht verdaut und gab auch mit $0,1 \% \mathrm{HCl}$ extrahirt nur Spuren von Pepsin, während ein Stück Fleich, welches bei einem anderen Frosche in den vom Magen abgeschnürten Oesophagus gelegt wurde, sich und beigefügtes Fibrin binnen kürzester Zeit in der HCl auflöste." Dieser Versuch zeigt also die äusserst geringe peptische Kraft der vom Oesophagus abgetrennten lebenden Magenschleimbaut, wovon sich also Fränkel durch seinen Versuch eben- 
falls überzengt hat. $\mathrm{Er}$ zeigt aber auch andererseits die ausserordentlich starke peptische Kraft des Oesophagus, gegen welche diejenige des Magens beinahe versebwindet, woruber Fränkel keine vergleichenden Versuche angestellt hat, jedenfalls keine mittheilt.

Fränkel hat also nicht mehr, sondern weniger gesehen als wir. Wenn er nun aus diesen Beobachtungen und Versuchen schliesst, dass in dem Magen der Frösche Säure und Pepsin gebildet wird, so ist er unserer Meinung nach zu diesem Sebluss in keiner Weise berechtigt, denn er hat nur gefunden, dass man in dem vom Oesophagus getrennten Magen Spuren von Pepsin nachweisen kann. -

Wenden wir uns kurz noch zu seinen VersuehsMethoden. Fränkel sagt zunächst, „dass er auf eine Kritik der von Swiecicki angewendeten Methoden nicht näher eingehen will". Wir wissen nicht, was er mit dieser Redewendung sagen will. Gemeiniglich würde man darunter verstehen, dass besagte Methoden eben die Kritik nicht aushalten könnten, oder etwas kürzer und deutlicher gesagt, dass sie schlecht und unbranchbar sind. Nun, eine etwaige derartige Annahme fordert uns heraus, seine Methoden mit den unseren zu vergleichen. Swięcicki extrahirte nahezu gleiche Gewichtsmengen verschiedener bei $37^{\circ} \mathrm{C}$. getrockneter Schleimhautstücke mit gleichen Mengen Salzsäure von $0,1 \%$ und prüfte, wie schnell dergleichen Extracte Fibrinflocken aufösen. Wir wiissten nicht, was man gegen diesc Methode einznwenden hätte, wenn man eben wissen will, wie viel man Pepsin aus einer Schleimhaut zu extrahiren im Stande ist.

Wie verfährt Fränkel? Er nimmt zunächst 10 Frösche statt eines einzigen und verarbeitet deren Schleimbäute gemeinschaftlich. Warum, ist uns nicht klar; denn das Material eines Frosehes ist über und über ausreichend, um mit ihm allein Versuche anzustellen. Verfeinert wird hierdurch die Methode unter keinen Umständen. Diese zerhackten und zerkleinerten Schleimbantstïcke unterwirft er nun weiter einer merkwürdigen Extractionsmethode, deren Wesen uns ebenfalls nicht rerständlich ist. Er bringt sie in Filter und lässt sie 24 Stunden lang mit grossen Mengen Wasser in Berübrung. Alles wird, damit es nicht fault, in die Kälte gestellt. Anfänglich entzieht das Wasser der Schleimhaut ihre löslichen Stoffe, später nicht mehr. Das ist nicht wunderbar, aber jedenfalls ganz unnütz nnd unzweckmässig; denn 
642 P. Grützıer u. H. v. Swiegcicki: Bomerküngen über d. Physiologie etc.

man verliert hierdurch nahezu jedes Urtheil uber die Menge von Ferment oder Vorferment, welches in der Schleimhant angehäuft ist.

Warum Fränkel nicht wie alle anderen Experimentatoren das Ferment oder Vorferment durch Salzsäure oder Glycerin extrahirt, sondern die Schleimhäute diesen höchst umständlichen und unzweckmässigen Waschceremonien unterworfen hat, ist uns, wie gesagt, nicht verständlich.

Wenn wir schon oben die Behauptung aussprechen mussten, dass Fränkel die Frage über die Säure- und Pepsinbildung in dem Verdauungskanal der Batrachier durch Beibringung neuer Thatsachen nicht gefördert hat, ja sogar nicht einmal so viel wie Swi pcicki gesehen hat (denn es fehlen bei ihm alle quantitativen Angaben), so müssen wir jetzt weiter noch hinzufügen, dass seine und unsere Arbeiten schon längst weit überholt sind durch vortreffliche und eingehende Untersuchungen, die namentlich Langle ${ }^{1}$ ) iber die betreffende Frage veröffentlicht hat.

Was also die Pepsinbildung in der Magenschleimhaut der Batrachier anlangt, so haben ja zunächst die sorgfältigen Untersuchungen von $\mathrm{Partsch}^{2}$ ), welche Fränkel nicht erwähnt, gezeigt, dass bei verschiedenen Batrachiern (namentlich den geschwänzten) gar keine besonderen Oesophagusdrüsen sich vorfinden, dass also bei diesen Thieren die Säure. und Fermentbildung an eine Zellenart gebunden ist. Bei den Fröschen ist eben die Sache anders; bier baben wir besondere Ferment bereitende Organe ausserbalb des Magens und in seiner Schleimhaut sicherlich (den Belegzellen ähnliche) Zellen, welche Säuren bilden.

Dass diese Zellen nun aller Wahrscheinlichkeit nach neben der Säure auch noch Pepsin bilden, dass sie sich also ähnlich wie die Zellen der Magenschleimhaut verwandter Batrachier verhalten, dies haben nicht wir, am allerwenigsten Fränkel, sondern das hat in eingehender Weise durch das Mikroskop und den chemischen Versuch Langley gezeigt, auf dessen Arbeit hier näher einzagehen nicht der Ort ist, wohl aber die Gelegenheit, die auf diesem Felde arbeitenden Forscher, in erster Linie Fränkel auf sie aufmerksam zu machen.

1) Philos. transact. of the royal society 1881. Part. III.

2) Archiv für mikrosk. Anatomie. Bd. 14, S. 179. 
Archiv f. d. ges. Physiologie. Bd. 49.

Tafel $I$.

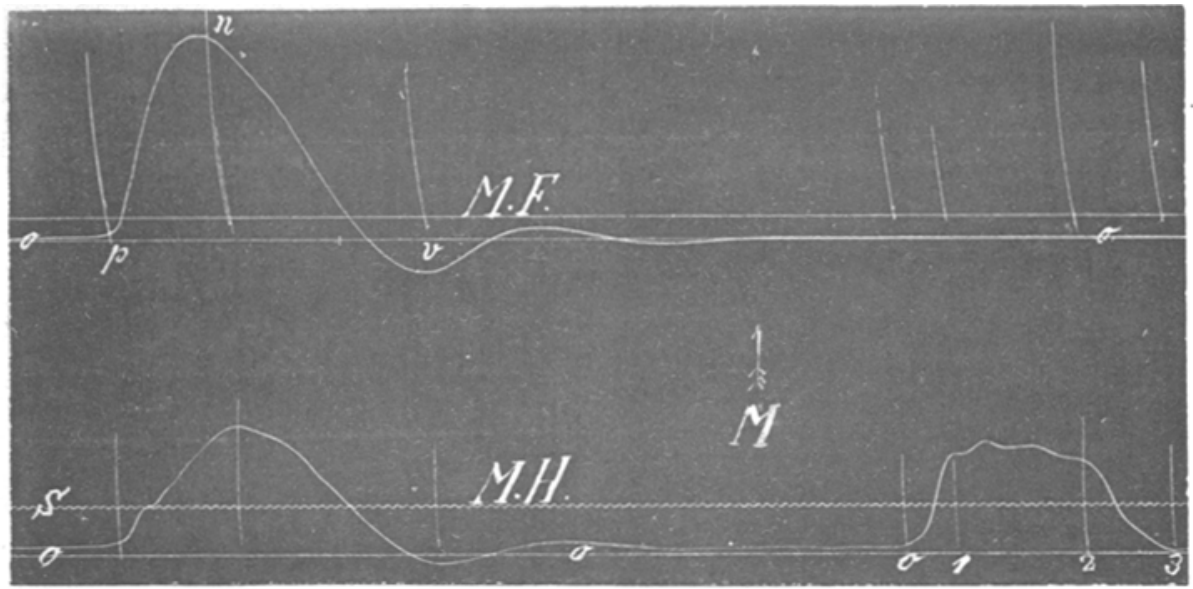

Fig. 1 a.

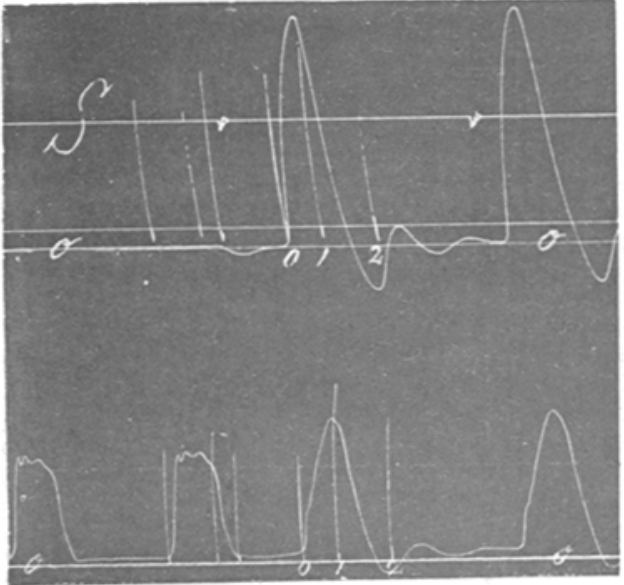

Fig. 1 b.

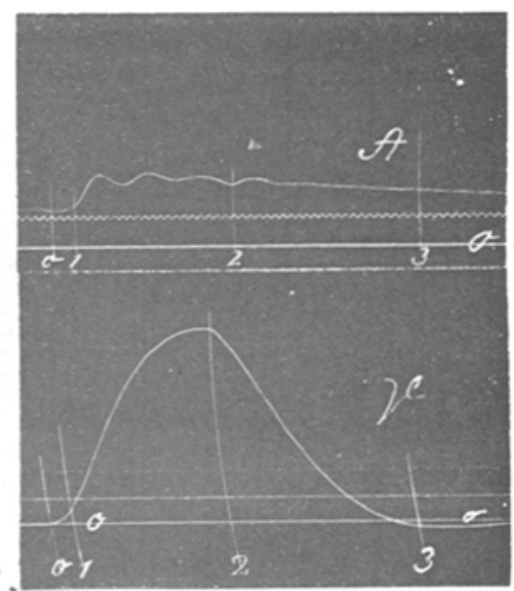

Fig. 2.

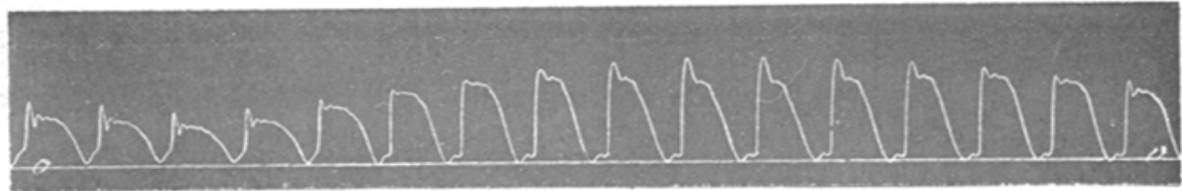

Fig. 3.

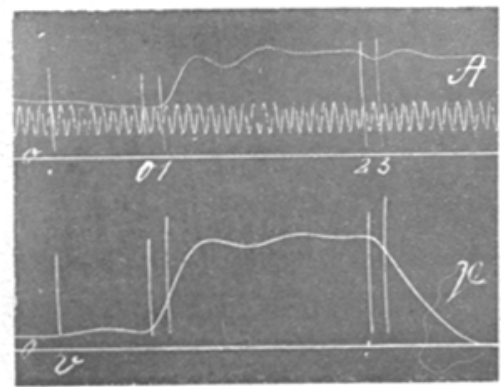

Fig. 4 a.

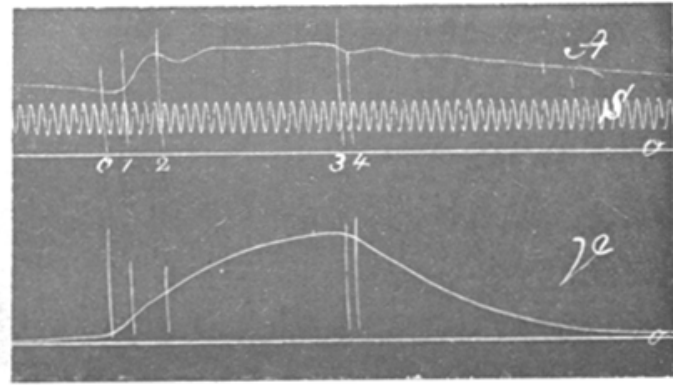

Fig. 4 b. 
Archiv f. d. ges. Physiologie. Ed. 49.

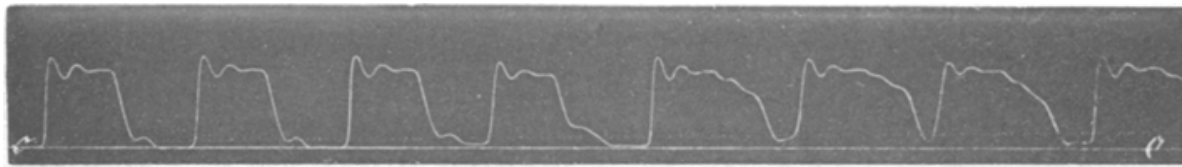

Fig. 5.

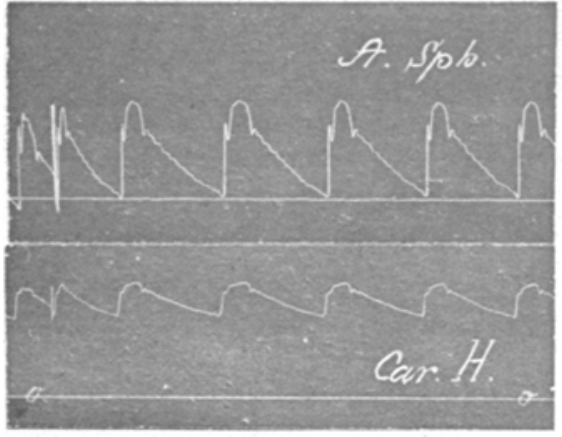

Fig. 6 a.

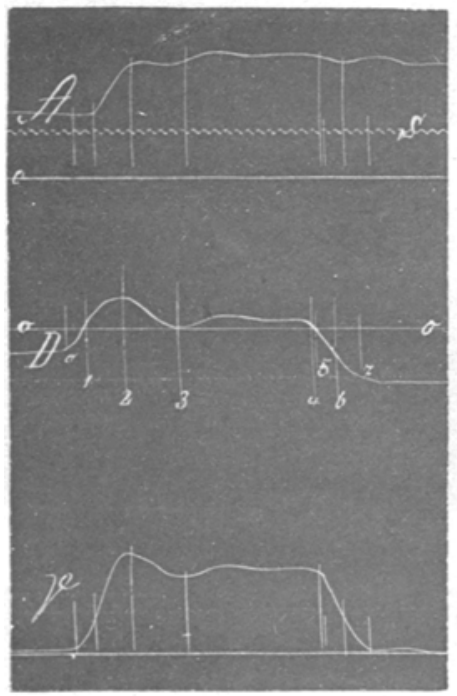

Fig. 7.

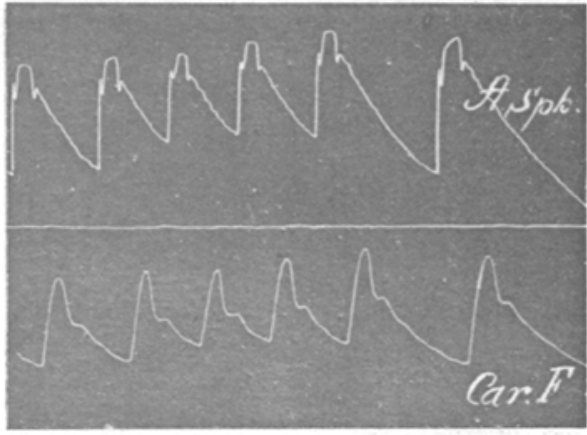

Fig. 6 b.

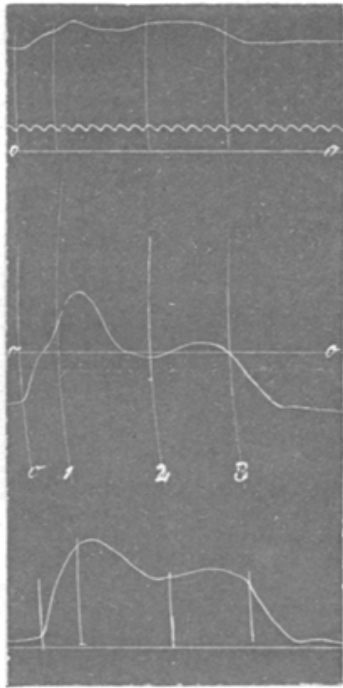

Fig. 8.

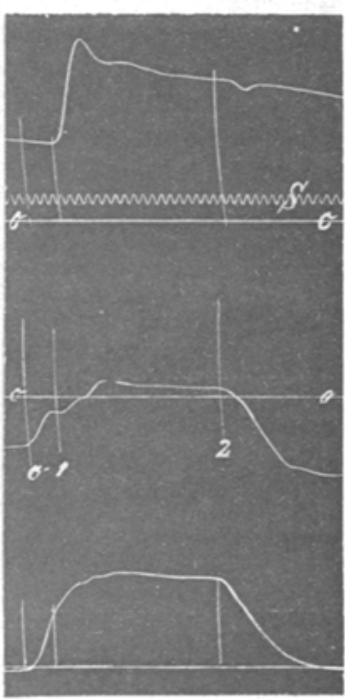

Fig. 9.

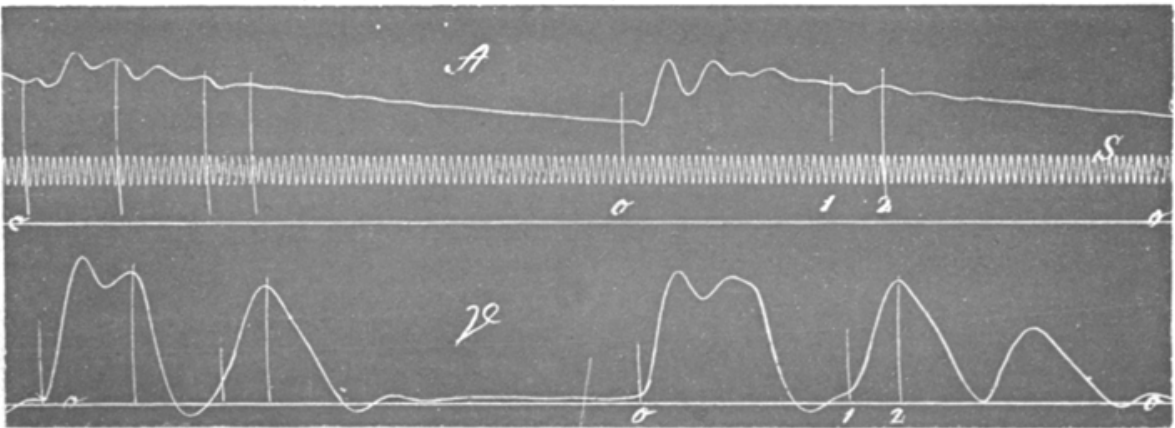

Fig. 10. 
Archiv f. d. ges. Physiolngie. Bd. 49.

Tafel III.

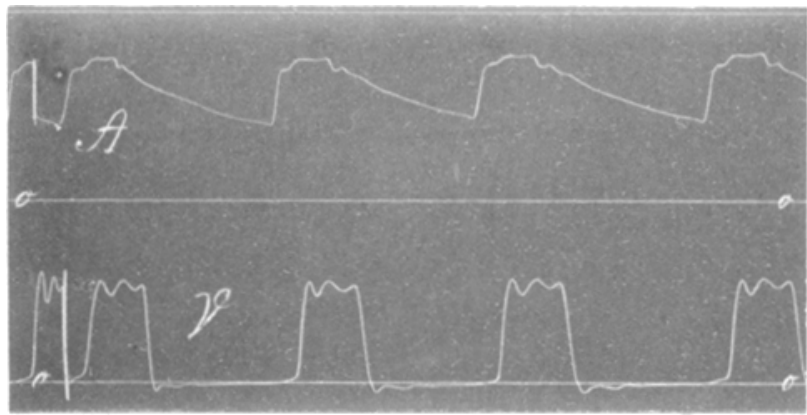

Fig. 11 a.

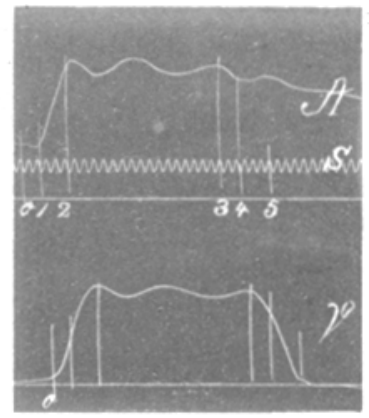

Fig. 11 b.

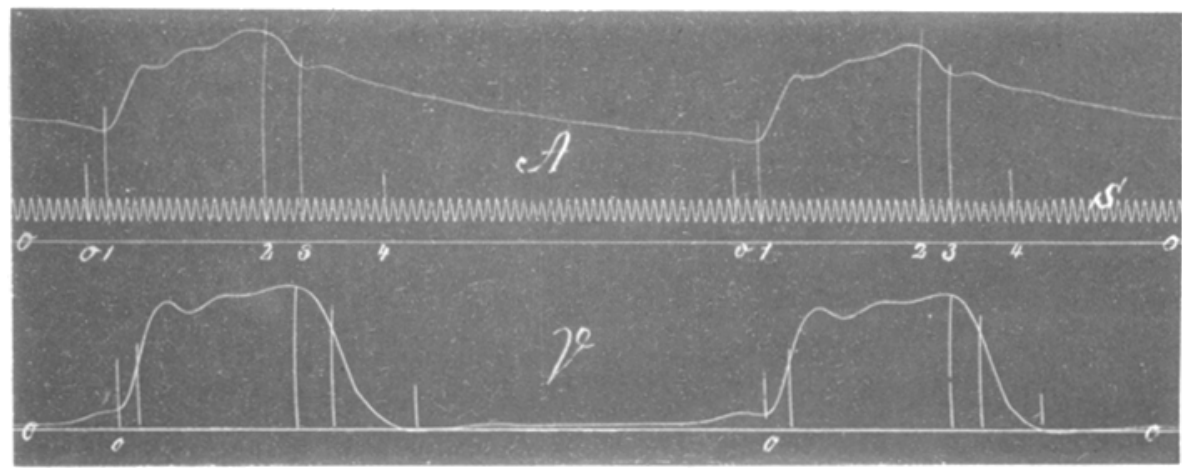

Fig. 12.

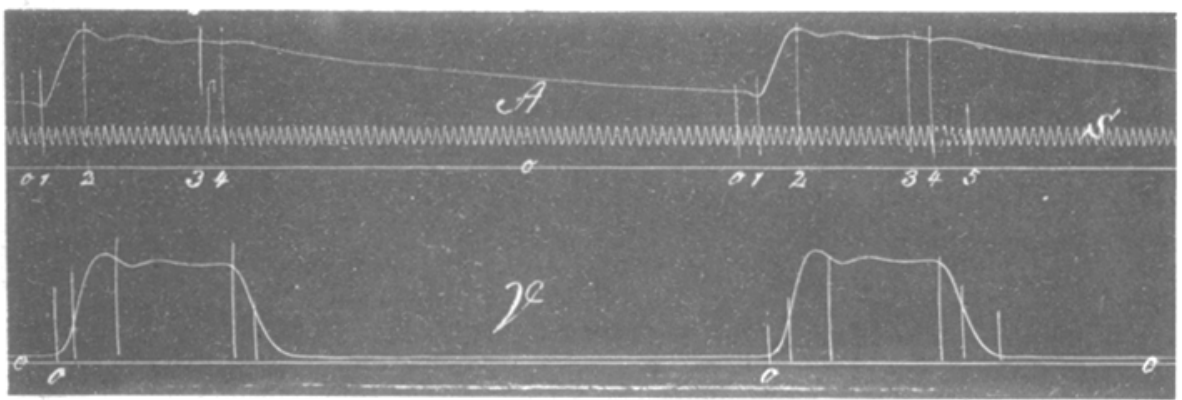

Fig. 13.

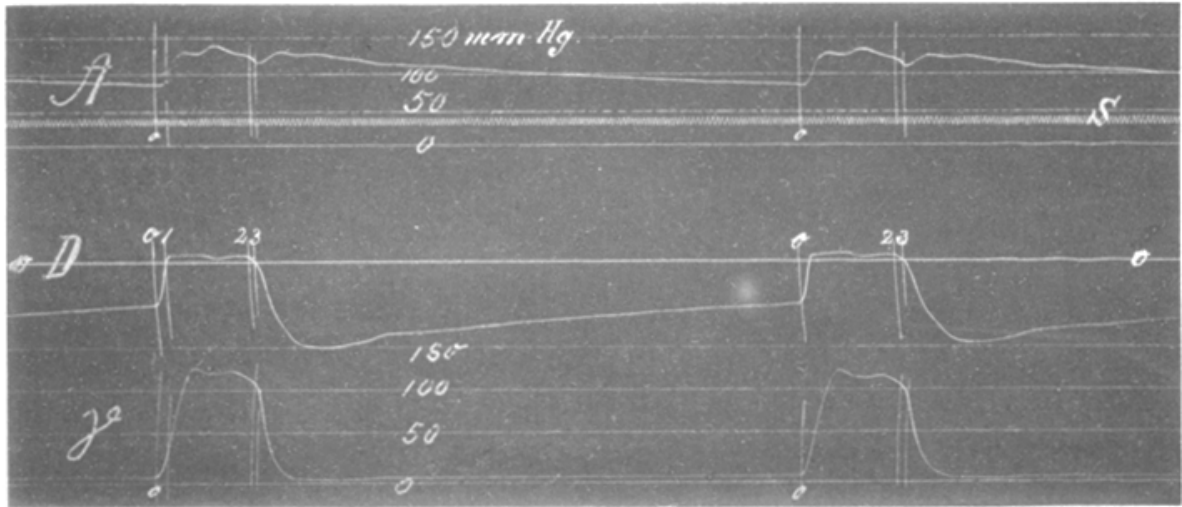

Fig. 14. 
Archiv f. d. ges. Physiologie. Bd. 49.

Tafel IV.

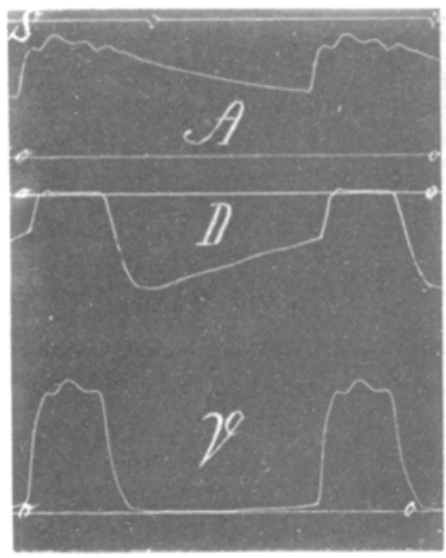

Fig. 15 a.

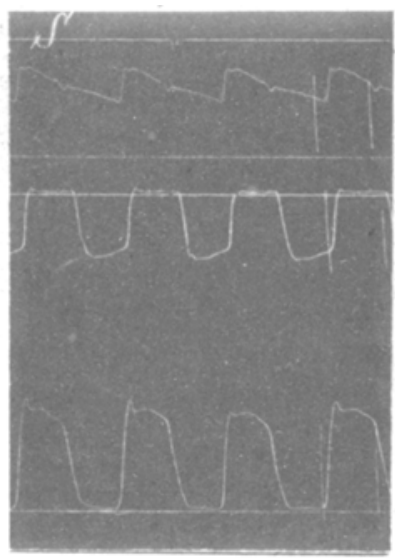

Fig. 15 b.

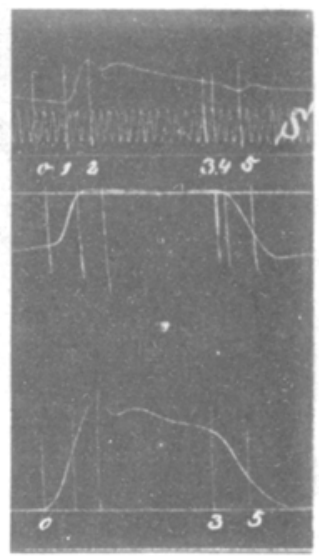

Fig. $15 \mathrm{c}$.

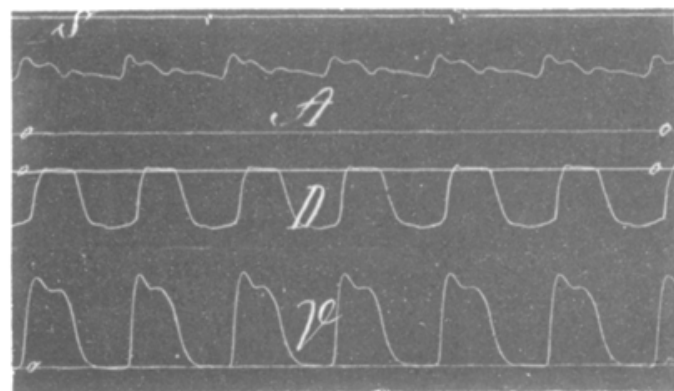

Fig. $15 \mathrm{~d}$.

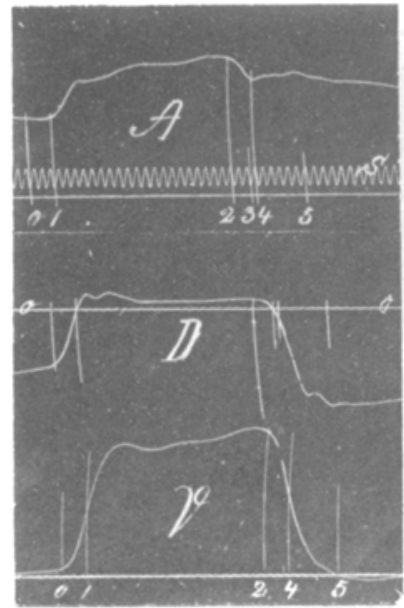

Fig. 16 .

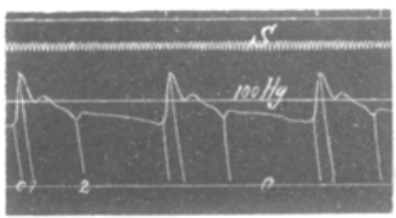

Fig. 19 a.

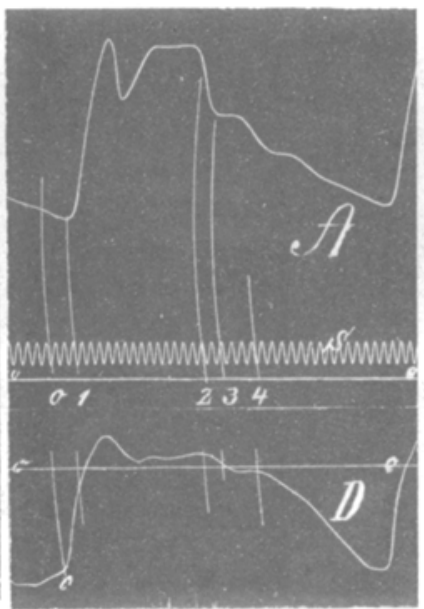

Fig. 17.

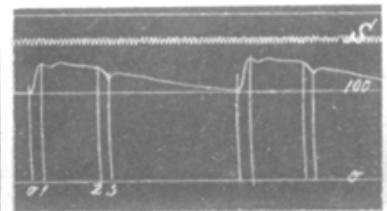

Fig. 19 b.

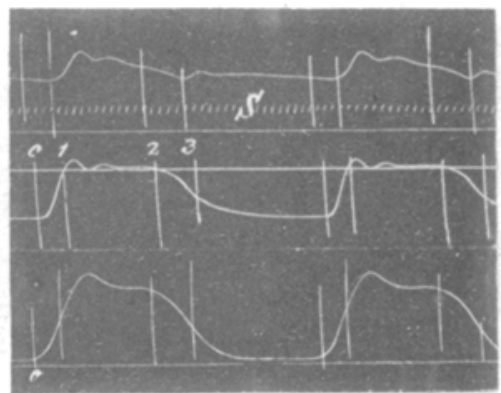

Fig. $15 \mathrm{e.}$

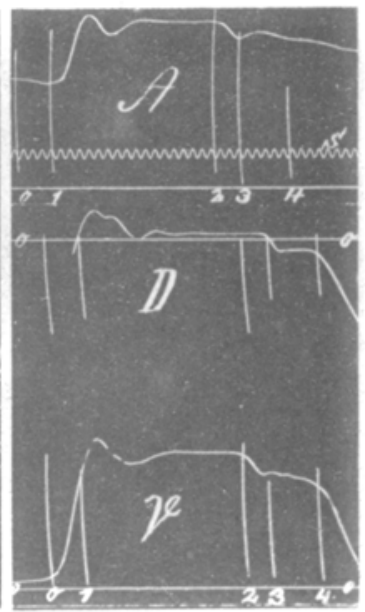

Fig. 18.

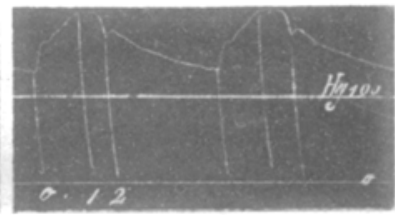

Fig. $19 \mathrm{c}$.

Liehtdruek von Kühl \& Co., Frankfurt a. M. 
Archiv f. d. ges. Plysiologie. Ld. 49.

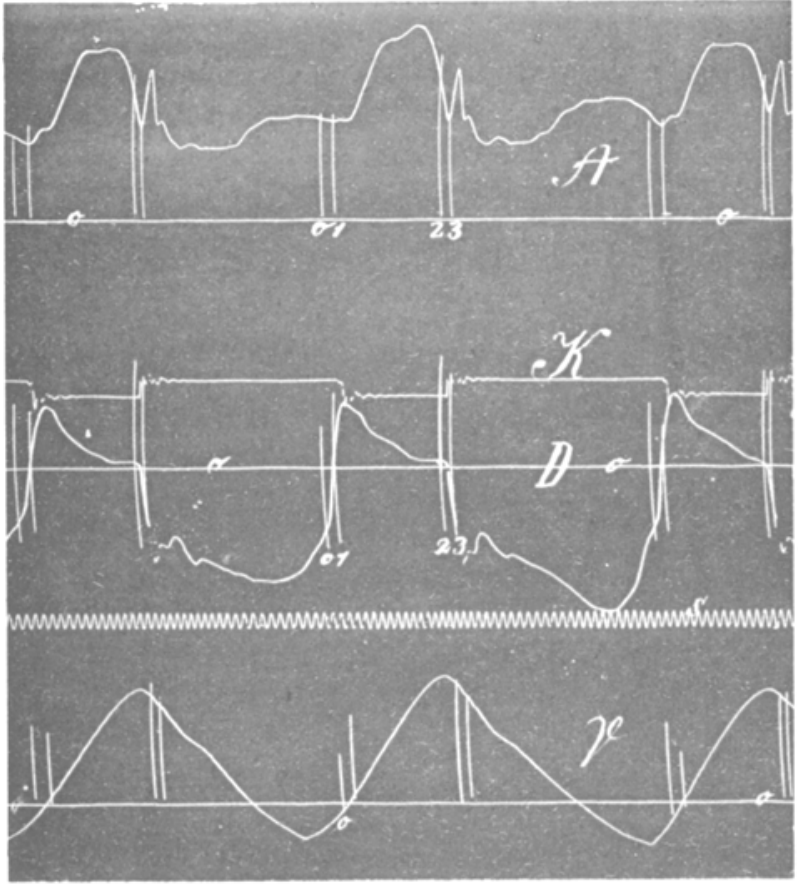

Fig. 20.

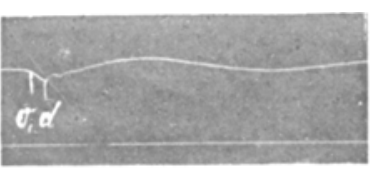

Fig. 21 :.

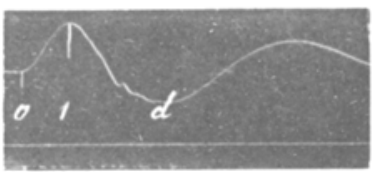

Fig. 21 b.

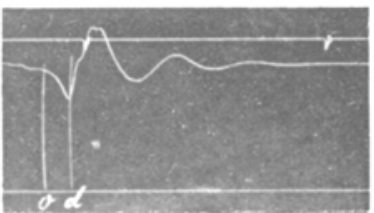

Fig. 22 : 1 .

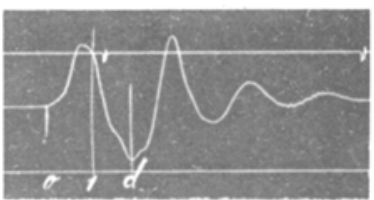

Fig. 22 b.

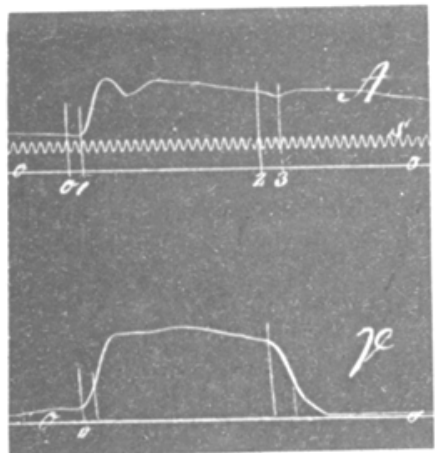

Fig. 23 a.

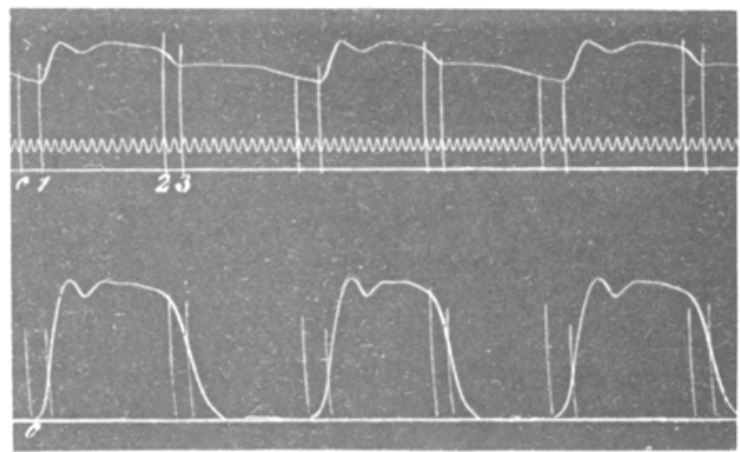

Fig. 23 h.

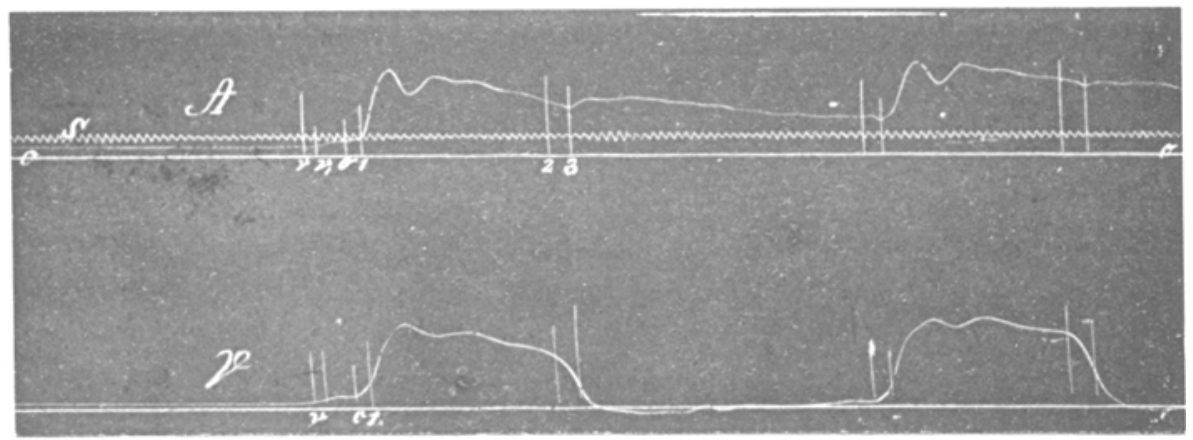

Fig. $23 \%$ 
Archiv f. d. ges. Physiologie. Bd. 49.

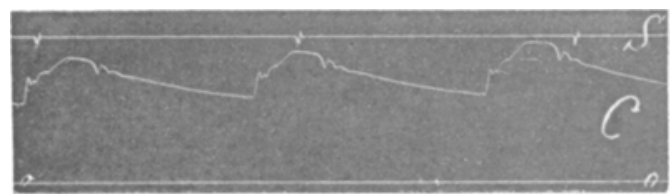

Fig. 24a.

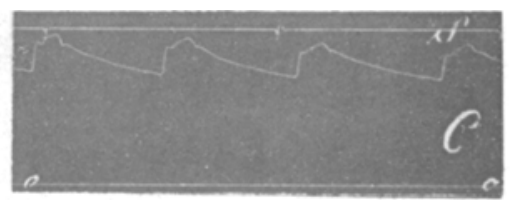

Fig. 24 b.

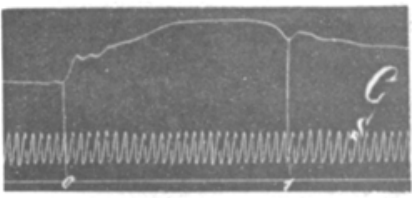

Fig. $24 \mathrm{c}$.

Fig. 24 d.

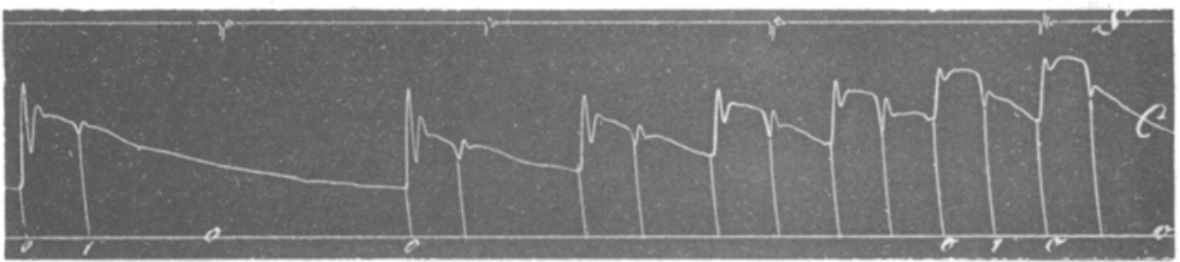

Fig. 25 .

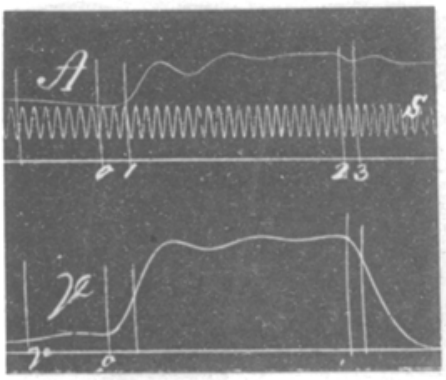

Fig. 26 a.

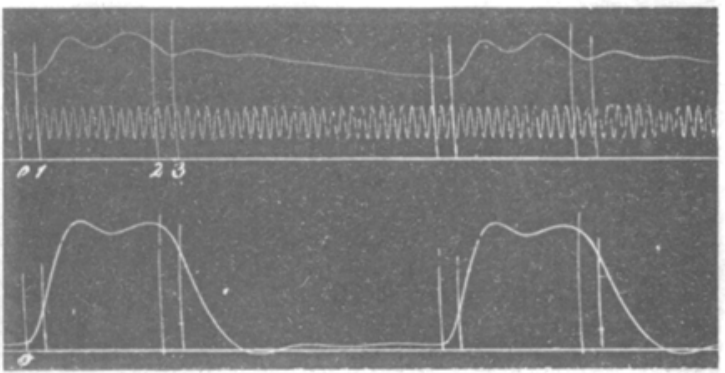

Fig. 26 b.

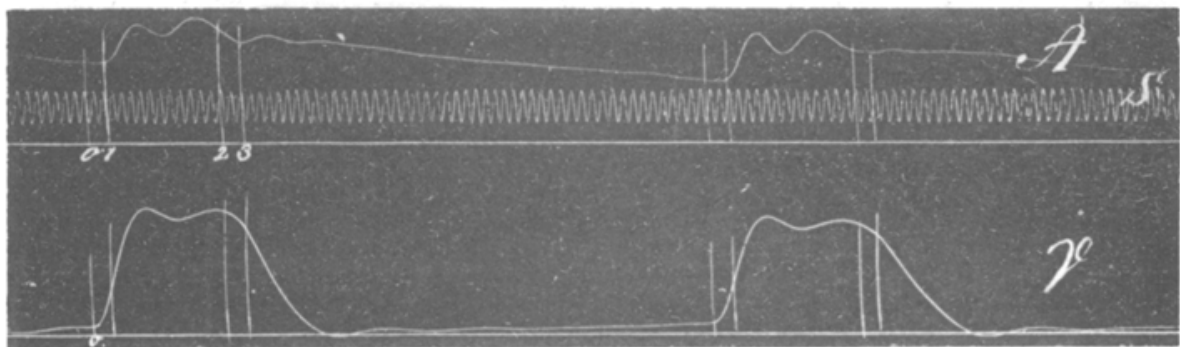

Fig. $26 \mathrm{c}$.

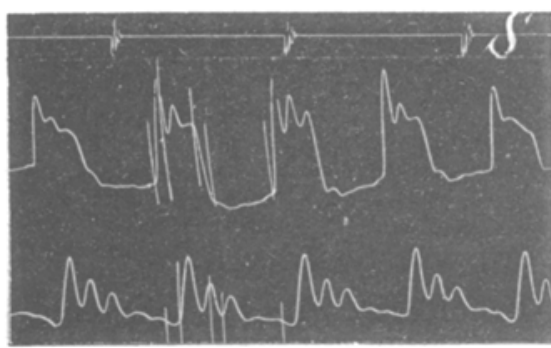

Fig. 27 a.

liclitdrizek von Kühl \& C $v$, Frankfurt a. M.

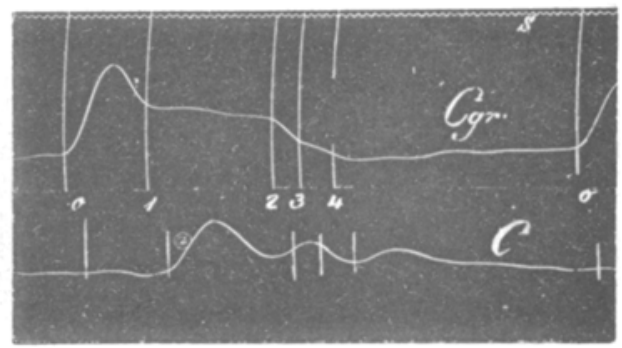

Fig. 27 b.

Verlag von Finil Strausa, Boun. 
Archiv f. d. ges. Physiologie. Bd. 49.

I'afel VII.

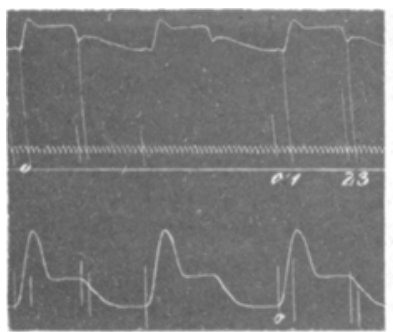

Fig. 28 a.

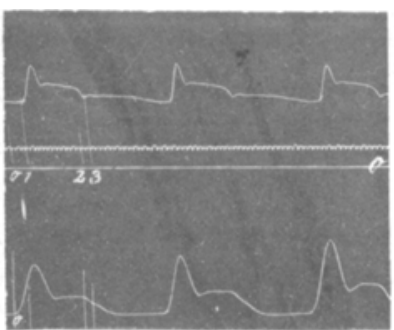

Fig. 28 b.

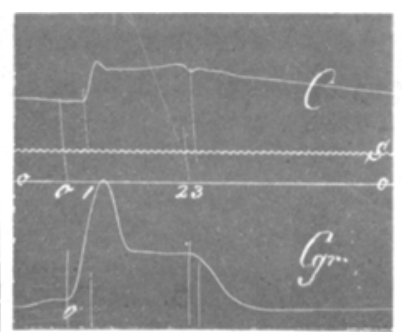

Fig. $28 \mathrm{c}$.

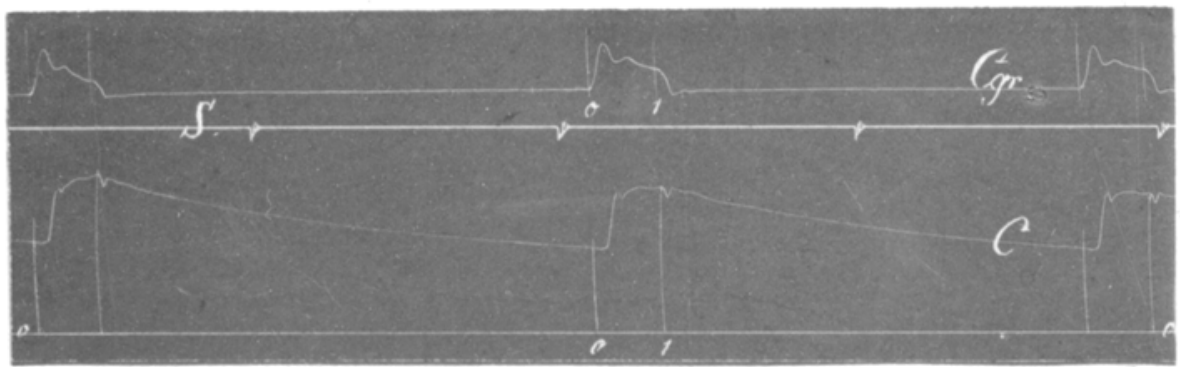

Fig. 29 a.

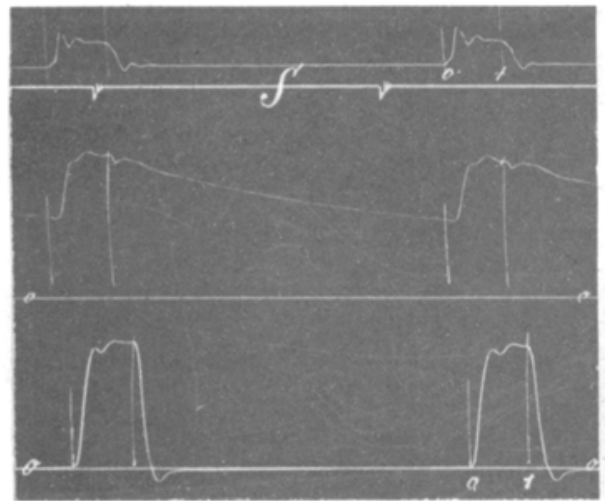

Fig. 29 b.

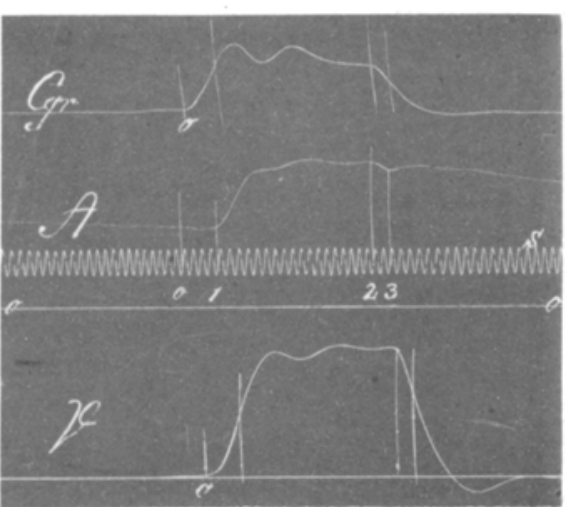

Fig. $29 \mathrm{c}$.

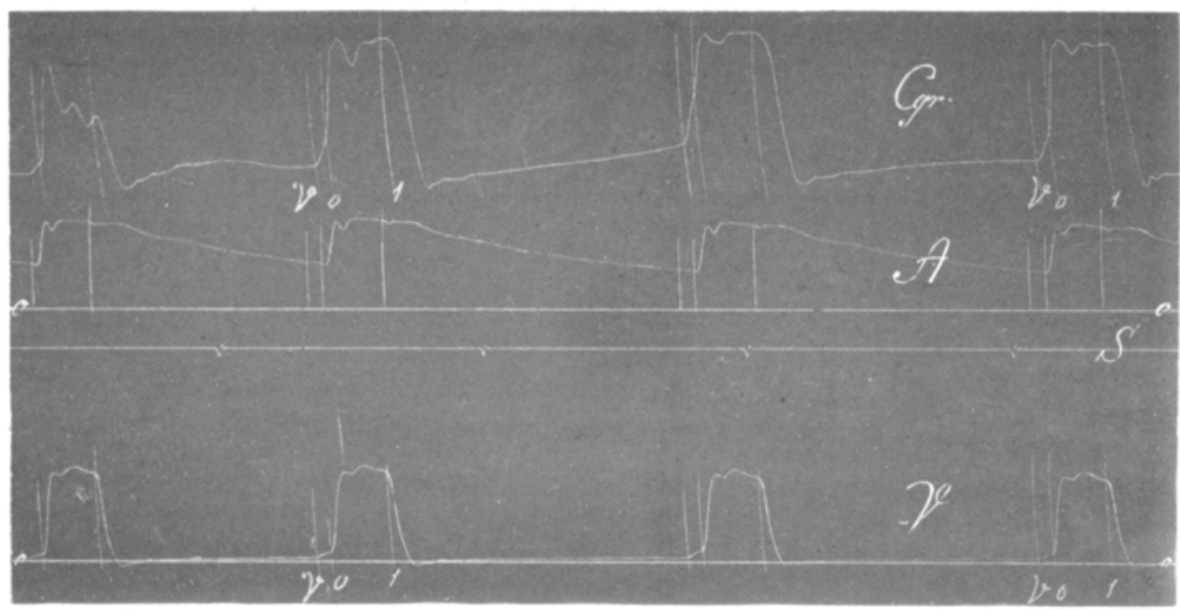

Fig. 30 . 

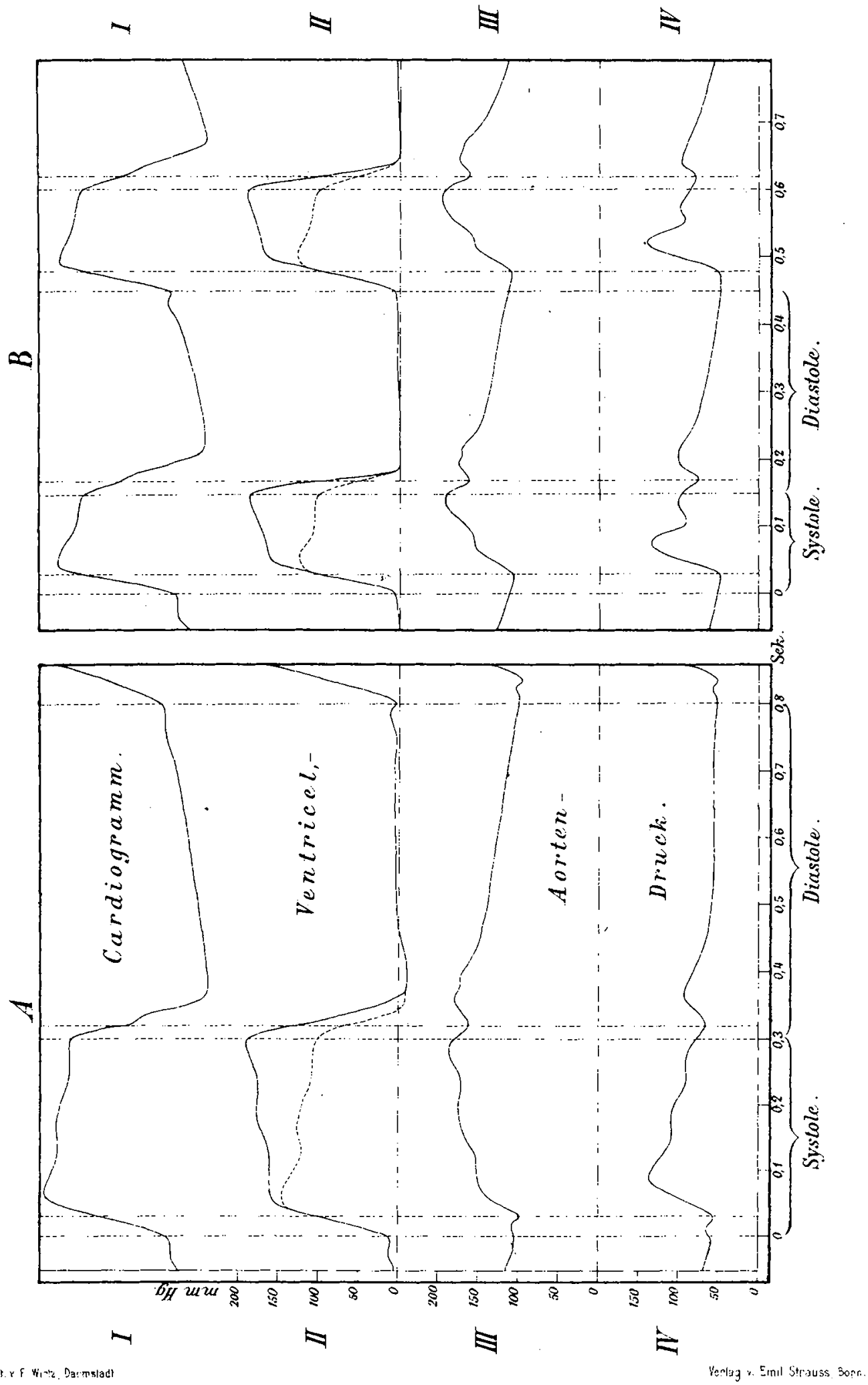
Fig. 1.
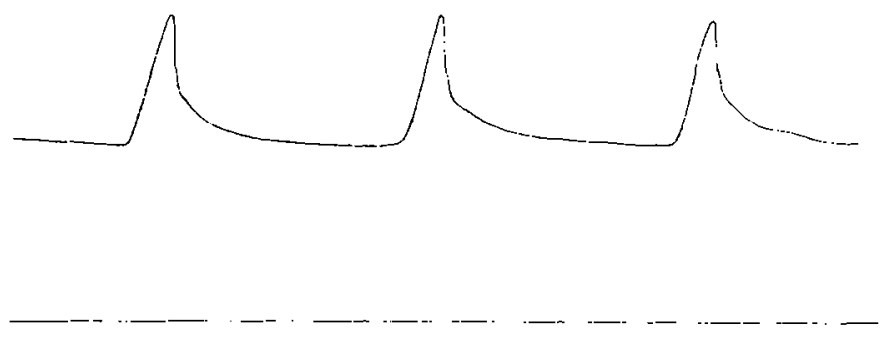

rig. 2.

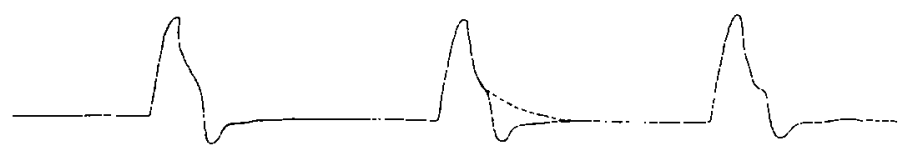

Fig. 3

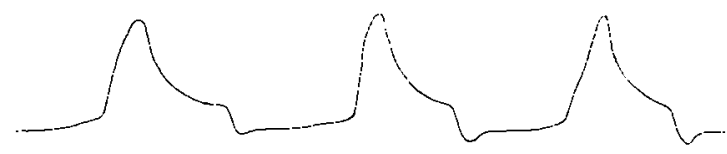

Fic 4.

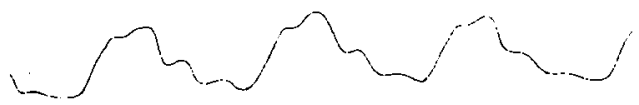




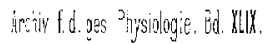
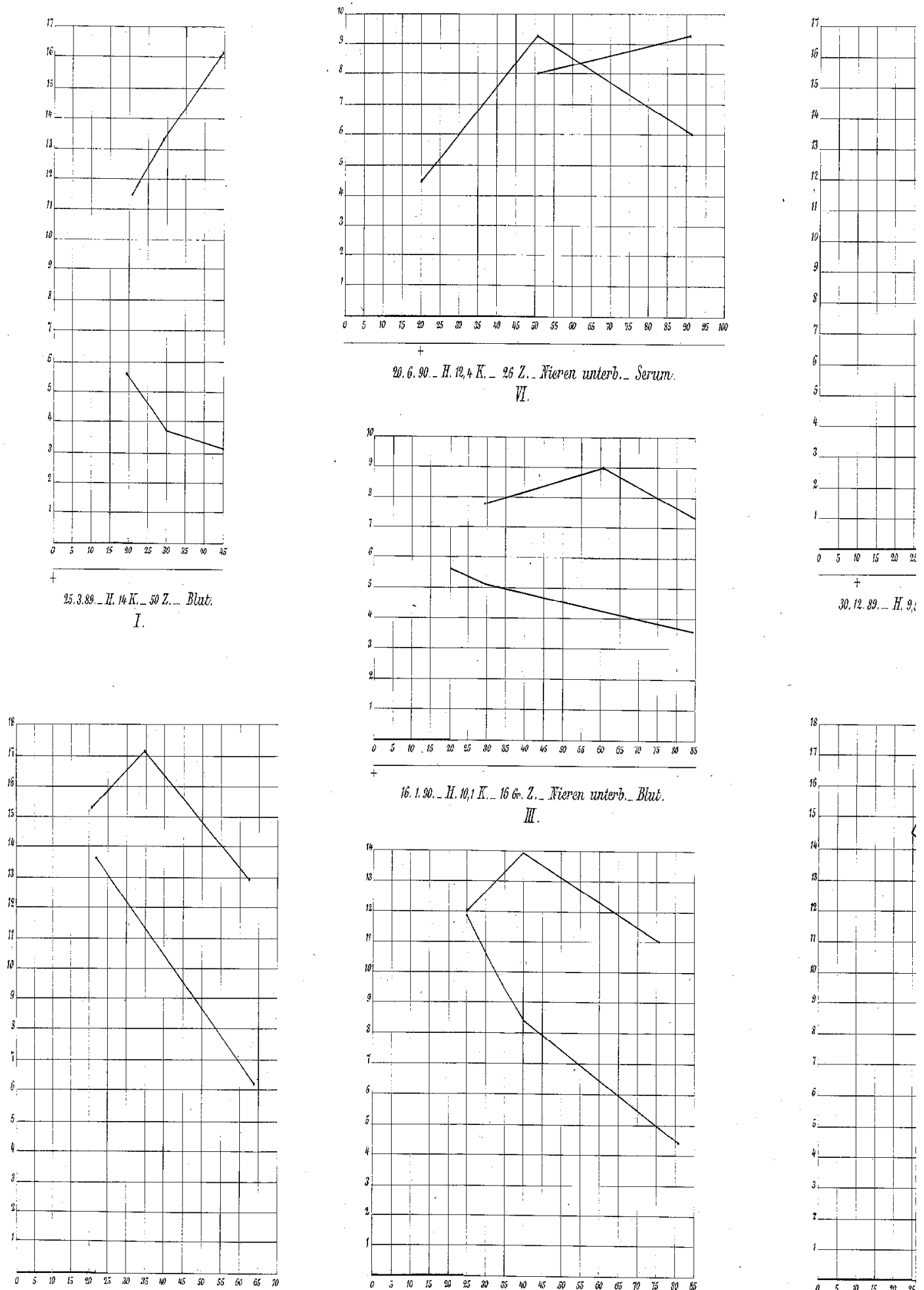

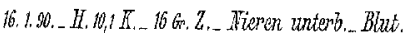

III.

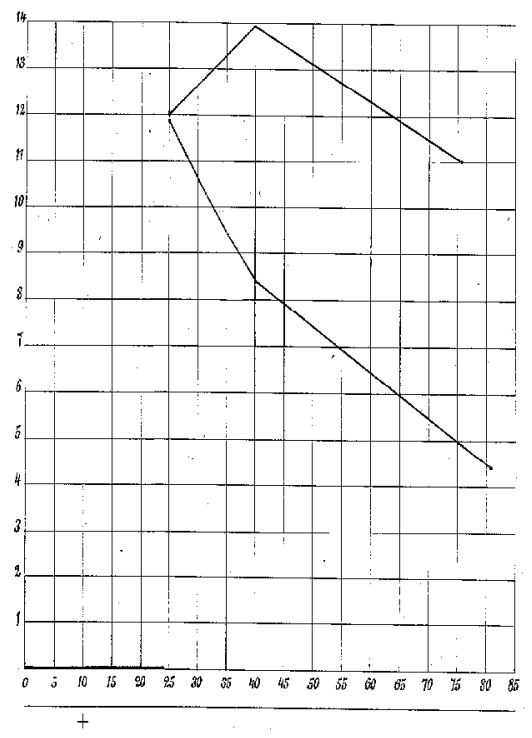

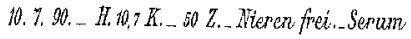

T.

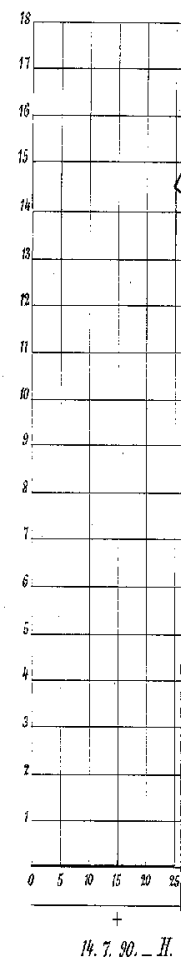




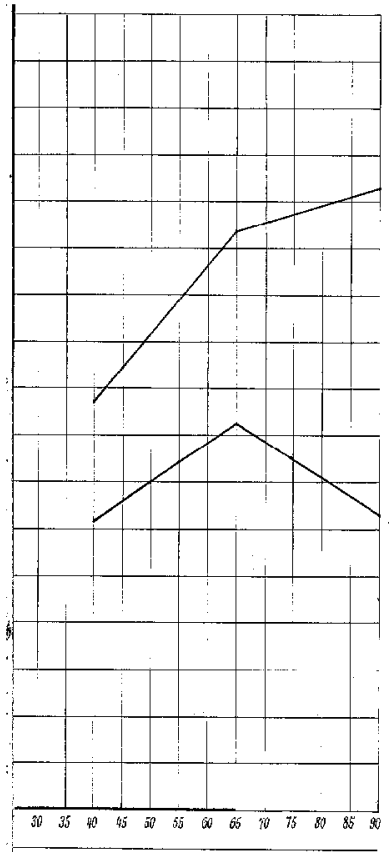

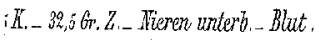
II.

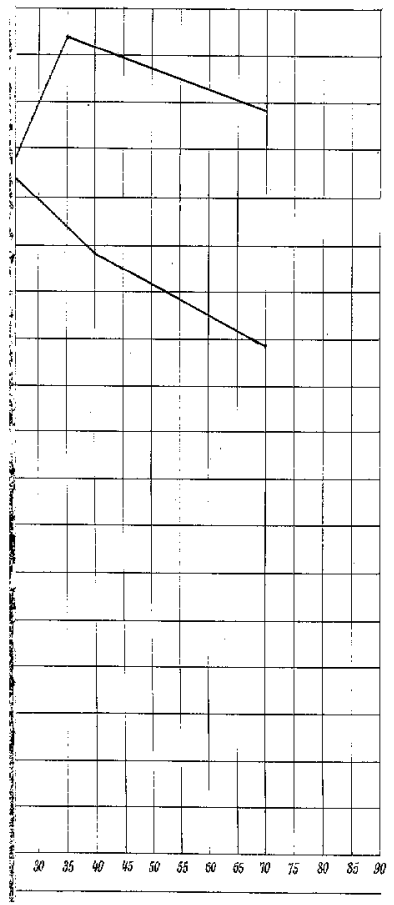

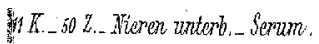

III.

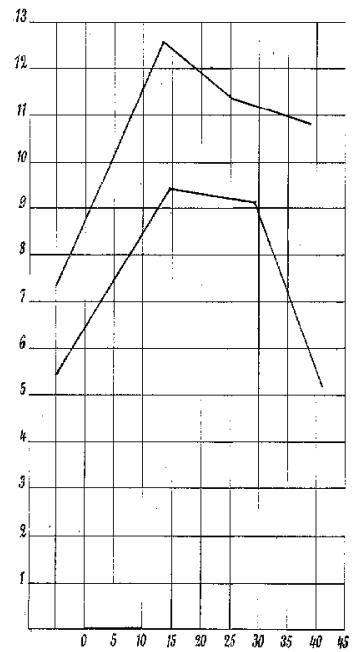

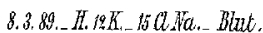

VIII.

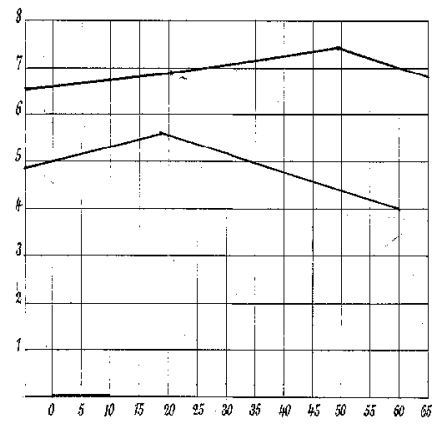

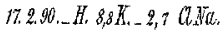

X.

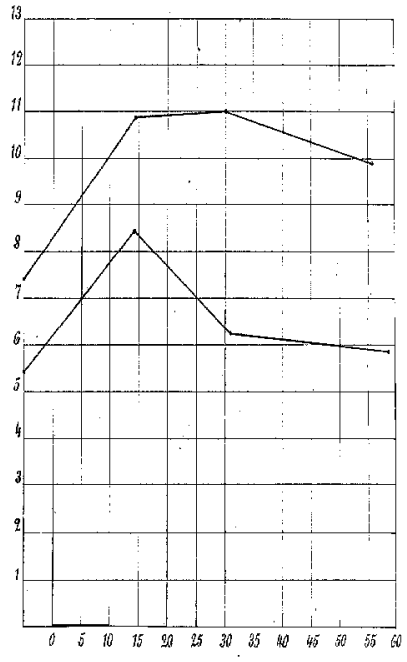

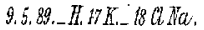

IX.

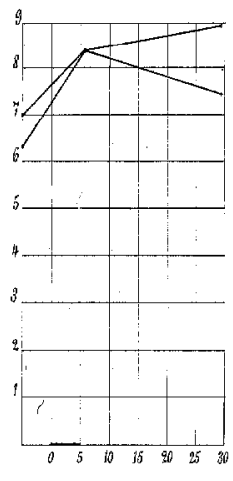

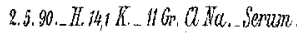
II.

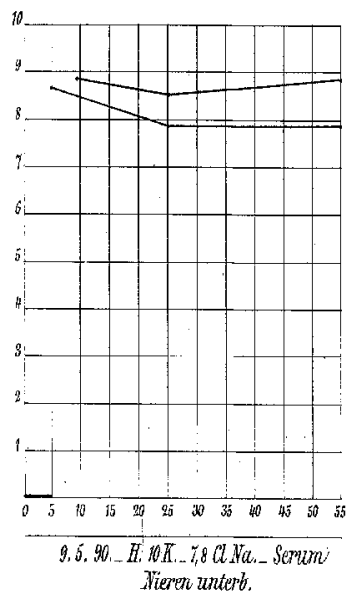

XII

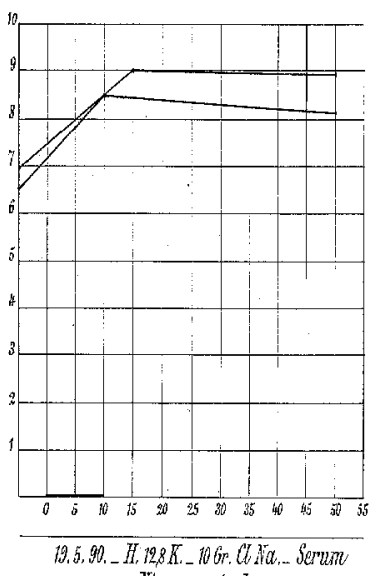
Niverer unters.

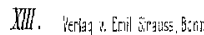

